\title{
Pregnancy outcomes in women with type 1 diabetes using insulin degludec
}

\author{
Lene Ringholm ${ }^{1,2}$ (D) Nicoline Callesen Do ${ }^{1,2,3} \cdot$ Peter Damm ${ }^{1,3,4} \cdot$ Elisabeth Reinhardt Mathiesen ${ }^{1,2,3}$
}

Received: 5 October 2021 / Accepted: 21 December 2021 / Published online: 11 February 2022

(C) Springer-Verlag Italia S.r.l., part of Springer Nature 2022

\begin{abstract}
Aims To evaluate pregnancy outcomes in a real-world setting of pregnant women with type 1 diabetes using the ultra-longacting insulin analog degludec compared to other long-acting insulin analogs throughout pregnancy.

Methods This was a secondary analysis of a prospective cohort study. The prospective cohort included consecutive, singleton pregnant women with type 1 diabetes receiving long-acting insulin analogs both before and during pregnancy: 67 women using degludec compared to 95 women using other long-acting insulin analogs in a routine care setting.

Results Women using degludec had similar clinical characteristics as women using other long-acting insulin analogs including HbA1c at 9 gestational weeks [6.5 (6.2-6.9) \% (48 (44-52) mmol/mol) versus 6.5 (6.0-7.0) \% (47 (42-53) mmol/mol), $p=0.52]$ and at 35 gestational weeks $[6.0(5.6-6.5) \%(42(38-47) \mathrm{mmol} / \mathrm{mol})$ versus $6.1(5.6-6.5) \%(43(38-48) \mathrm{mmol} /$ $\mathrm{mol}), p=0.68]$. Pregnancy outcomes were similar regarding preeclampsia $[10 \%(7 / 67)$ versus $8 \%(8 / 95), p=0.66]$ and preterm delivery before 37 gestational weeks [16\% (11/67) versus 23\% (22/95), $p=0.29]$. There were no perinatal deaths, and neonatal outcomes as large for gestational age infants [37\% (25/67) versus 39\% (37/95), $p=0.83$ ], small for gestational age infants [4\% (3/67) versus 5\% (5/95), $p=1.0]$ and neonatal hypoglycemia [32\% $(21 / 65)$ versus $41 \%(34 / 83), p=0.28]$ were similar between women using degludec and other long-acting insulin analogs.

Conclusions The use of degludec during pregnancy resulted in similar pregnancy outcomes as use of other long-acting insulin analogs in women with type 1 diabetes in a real-world setting. This suggests that degludec initiated before pregnancy can be continued throughout gestation.
\end{abstract}

Keywords Pregnancy $\cdot$ Type 1 diabetes $\cdot$ Degludec $\cdot$ Long-acting insulin analog $\cdot$ Pregnancy outcomes $\cdot$ Neonatal outcomes

This article belongs to the topical collection Pregnancy and Diabetes, managed by Antonio Secchi and Marina Scavini

Lene Ringholm

lene.ringholm.02@regionh.dk

1 Center for Pregnant Women with Diabetes, Rigshospitalet, Blegdamsvej 9, 2100 Copenhagen, Denmark

2 Department of Endocrinology and Metabolism PE7652, Rigshospitalet, Blegdamsvej 9, 2100 Copenhagen, Denmark

3 Department of Clinical Medicine, Faculty of Health and Medical Sciences, University of Copenhagen, Blegdamsvej 3b, 2200 Copenhagen, Denmark

4 Department of Obstetrics, Rigshospitalet, Blegdamsvej 9, 2100 Copenhagen, Denmark

\section{Introduction}

The choice of insulin for the management of diabetes has increased markedly over the last decade with the availability of different insulin analogs. However, during pregnancy insulin choice is largely determined by its safety profile [1].

Insulin analogs are now widely used in pregnancy $[2,3]$. The safety and efficacy of insulin detemir have been evaluated in both a randomized controlled trial (RCT) [4] and a cohort study [5]. Observational data on pregnancies exposed to insulin glargine do not indicate any adverse effects on pregnancy outcomes [6-8].

Insulin degludec is a newer ultra-long-acting insulin analog on the market with a half-life of $25 \mathrm{~h}$, a duration of action exceeding $42 \mathrm{~h}$ [9] and documented efficacy and safety outside of pregnancy with improved glycemic control and lower risk of hypoglycemia compared to insulin glargine [10-12]. Insulin degludec is now widely used in Denmark in 
the non-pregnant population of persons with type 1 diabetes (personal communication). Insulin degludec is currently used off-label during pregnancy in women with type 1 diabetes by us and others, as documented in case reports including in total 10 women who all delivered liveborn infants without congenital malformations [13-17]. However, only four of these women used insulin degludec before and throughout pregnancy [13, 16, 17].

Shifting the type of long-acting insulin in early pregnancy may lead to fluctuating glucose levels. Therefore, since the launch of insulin degludec in 2013 [18] it has been the policy at our center that women who have obtained good glycemic control and who are satisfied with using insulin degludec before conception can continue to use this insulin during pregnancy.

Previously we reported similar glycemic control and pregnancy outcomes in the first 22 women in our center using insulin degludec initiated before pregnancy compared to women using insulin glargine [19].

In this study, we aimed to evaluate pregnancy outcomes in a real-world setting of women with type 1 diabetes using insulin degludec compared to other long-acting insulin ana$\operatorname{logs}$ throughout pregnancy.

\section{Subjects, material and methods}

This was a secondary analysis of a prospective observational cohort of pregnant women with type 1 or type 2 diabetes focusing on preeclampsia [20,21].

For this study, consecutive pregnant women with type 1 diabetes referred $<20$ weeks with a single living fetus to Center for Pregnant Women with Diabetes, Rigshospitalet, were included from February 2016 to February 2020 and followed in our center during pregnancy until discharge after delivery. Exclusion criteria were age $<18$ years, insufficient Danish language skills, study participation in a previous pregnancy and severe concomitant diseases. Of 257 women with type 1 diabetes included in the primary study, 94 women on insulin pump treatment and one woman receiving insulin degludec as part of an RCT were excluded leaving 162 women for this study. Fifteen of the women using insulin degludec were also included in our previous publication [19].

All women followed the routine diabetes and pregnancy care program for pregnant women with diabetes as previously described $[20,21]$. Briefly, the women were seen for clinical visits every second week where self-monitored blood glucose values, prevalence of mild hypoglycemia the last week (events with symptoms familiar to the women as hypoglycemia and managed by themselves $[22,23]$ ), $\mathrm{HbA} 1 \mathrm{c}$, insulin doses, blood pressure (BP), proteinuria (screened with a urine dipstick) and weight were evaluated.
For this study, HbA1c and hypoglycemia at median 9, 20 and 35 weeks are presented.

The type of insulin used from pregnancy onset was generally unchanged during pregnancy. The women using insulin degludec in the present study generally initiated treatment with this insulin as part of routine care prior to and unrelated to the current pregnancy and obtained improved glycemic control. Based on the individual woman's experience with insulin degludec, she was entitled to choose to continue this insulin during pregnancy, if she so wished, and when the benefits of continuing the usual insulin degludec in terms of good glycemic control were estimated to outweigh possible disadvantages. The women included in this study thus decided to continue using insulin degludec during pregnancy. However, no formal written informed consent to continue use of insulin degludec during pregnancy was obtained.

Antihypertensive treatment was initiated or intensified if office $\mathrm{BP} \geq 135 \mathrm{mmHg}$ systolic and/or $\geq 85 \mathrm{mmHg}$ diastolic in combination with home $\mathrm{BP} \geq 130 \mathrm{mmHg}$ systolic and/ or $\geq 80 \mathrm{mmHg}$ diastolic when available, or if urinary albu$\mathrm{min} /$ creatinine ratio $\geq 300 \mathrm{mg} / \mathrm{g}$ [20].

Gestational weight gain was calculated from the last weight measured, often at 36 weeks, and self-reported prepregnancy weight [24].

Routine care changed slightly during the study period [20, 21]. Starting on February 23, 2018, aspirin $150 \mathrm{mg} /$ day was recommended for all women according to new international recommendations [25], vitamin D level was measured and targets for glycemic control changed slightly: Blood glucose monitoring (BGM) targets changed from $4.0-6.0$ to $4.0-5.5 \mathrm{mmol} / \mathrm{l}$ preprandially and from $4.0-8.0$ to $4.0-7.0 \mathrm{mmol} / \mathrm{l}$ postprandially. $\mathrm{HbA} 1 \mathrm{c}$ targets changed from $<6.7 \%(50 \mathrm{mmol} / \mathrm{mol})$ to $<6.5 \%(48 \mathrm{mmol} / \mathrm{l})$ before 20 weeks and from $<5.8 \%(40 \mathrm{mmol} / \mathrm{mol})$ to $<5.6 \%$ (38 $\mathrm{mmol} / \mathrm{mol}$ ) thereafter.

As part of the routine diabetes care program, the dose of insulin degludec and of other long-acting insulin analogs was titrated to the early morning preprandial BGM target at each clinical visit during pregnancy, and women were instructed to adjust their dose of insulin degludec or other long-acting insulin analog, respectively, when indicated every 3-5 days between clinical visits. If indicated, the dose of other long-acting insulin analog with a shorter duration of action than degludec was given twice daily both before breakfast and before dinner to obtain BGM targets.

Before February 23, 2018, aspirin was only prescribed to women with additional risk factors for preeclampsia (previous preeclampsia, chronic hypertension, microalbuminuria/ nephropathy or oocyte donation), and vitamin D level was not measured [20].

Sixteen (10\%) women were pregnant during the COVID19 pandemic with none testing positive for COVID-19. 
Preeclampsia was diagnosed in the presence of $\mathrm{BP} \geq 140 / 90 \mathrm{mmHg}$ with coexistence of proteinuria $\geq 1+$ on a urine dipstick and/or new onset of organ dysfunction [26]. Preterm preeclampsia was defined as delivery with preeclampsia $<37$ weeks. Preterm delivery was defined as delivery $<37$ weeks.

Birth weight $\mathrm{z}$-score was calculated to adjust for gestational age and sex [27], and large and small for gestational age (LGA and SGA) were defined as birth weight $>90$ th percentile and $<10$ th percentile, respectively.

The following neonatal outcomes were recorded: perinatal mortality (death between 22 weeks and one week after delivery), major congenital malformations (leading to death, causing significant future handicap or requiring surgery), neonatal hypoglycemia (plasma glucose $<2.2 \mathrm{mmol} / \mathrm{l}$ within $4 \mathrm{~h}$ after birth), transient tachypnea (requiring continuous positive airway pressure for $>60 \mathrm{~min}$ ), jaundice (requiring phototherapy) and admission to neonatal intensive care unit [21].

\section{Statistical Analysis}

Categorical data were given as number (\%) and compared using Chi-square test or Fisher's exact test. Continuous data were given as mean (SD) or median (interquartile range) and compared using unpaired t-test or Mann-Whitney U test depending on distribution. A statistical power analysis was not performed a priori for this secondary analysis. Associations were considered statistically significant at a two-sided $p$-value $<0.05$. All statistical analyses were performed by SPSS 25 (IBM Corp., Armonk, NY, USA).

\section{Results}

Sixty-seven (41\%) women used insulin degludec and 95 used other long-acting insulin analogs: insulin glargine $100(n=58(61 \%))$, insulin detemir $(n=24(25 \%))$, insulin glargine $300(n=9(10 \%))$, biosimilar insulin glargine 100 $(n=2(2 \%))$ and NPH insulin $(n=2(2 \%))$. At our center, the proportion of women becoming pregnant while using insulin degludec increased over the years being $9 \%$ in 2016, $30 \%$ in $2017,57 \%$ in $2018,66 \%$ in 2019 and $88 \%$ in 2020. Forty-nine $(73 \%)$ women using insulin degludec and 29 $(31 \%)(p<0.0001)$ women using other long-acting insulin analogs were included after implementation of the updated guidelines on February 23, 2018.

Mealtime insulin was insulin aspart, except in eight (12\%) women using faster-acting insulin aspart (fiasp) with insulin degludec, while two (2\%) used insulin fiasp and two (2\%) used insulin lispro with other long-acting insulin analogs.

Clinical characteristics of the women using insulin degludec were comparable to the remaining women (Table 1).
Vitamin D insufficiency (serum 25-hydroxy-vitamin $\mathrm{D}<50 \mathrm{nmol} / \mathrm{l})$ was diagnosed in 10 out of $46(22 \%)$ versus 6 out of 29 (21\%), $p=0.91$.

All maternal pregnancy outcomes including preeclampsia $(10 \%$ versus $8 \%, p=0.68)$ and preterm delivery $(18 \%$ versus $23 \%, p=0.39$ ) were similar between women using insulin degludec and other long-acting insulin analogs. There were no perinatal deaths, and all other neonatal outcomes including birth weight $z$ score, SGA and LGA infants were similar between the groups (Table 2). Labor dystocia was the main contributing factor for emergency cesarean section in 53\% (8 out of 15) of women using insulin degludec and in $48 \%$ (13 out of 27) of women using other long-acting insulin analogs, $p=0.75$.

\section{Discussion}

In this secondary analysis of prospectively collected data in women with type 1 diabetes using insulin degludec before and during pregnancy, similar pregnancy outcomes compared to women using other long-acting insulin analogs were seen. No clinical concerns by continuing insulin degludec during pregnancy were observed in this cohort.

This study supports the findings from our previous study of 22 women using insulin degludec from preconception until after delivery, where use of insulin degludec seemed safe [19].

We cannot rule out confounding by indication to a certain degree, as insulin degludec probably was prescribed pre-pregnancy to women who had dysregulated diabetes with hyperglycemia and/or problematic hypoglycemia with the aim of achieving better glycemic control. So much the more is it reassuring that glycemic control and pregnancy outcomes in women using insulin degludec were similar to those in women using other long-acting insulin analogs. The use of insulin degludec increased over time and the majority of women using insulin degludec were included after February 23, 2018, where slightly tighter glycemic targets and a new practice for aspirin prescription and measurement of vitamin D level were implemented [20] resulting in a higher prevalence of women prescribed aspirin in the insulin degludec group of the present study. However, the prevalence of preeclampsia, preterm delivery and LGA did not differ between women included before and after this date in the original cohort [20], and HbA1c, total insulin doses and prevalence of vitamin D insufficiency were similar between women using insulin degludec and other long-acting insulin analogs.

Since shifting the type of long-acting insulin in early pregnancy may lead to fluctuating glucose values, it was the policy at our center to let women who had obtained good glycemic control and who were satisfied with using insulin 
Table 1 Clinical characteristics in 162 women with type 1 diabetes using insulin degludec or other long-acting insulin analogs before and during pregnancy

\begin{tabular}{|c|c|c|c|}
\hline & $\begin{array}{l}\text { Insulin degludec } \\
(n=67)\end{array}$ & $\begin{array}{l}\text { Other long-acting insulin } \\
\text { analogs } \\
(n=95)\end{array}$ & $p$-value \\
\hline Maternal age (years) & $31 \pm 5$ & $31 \pm 6$ & 0.94 \\
\hline Duration of diabetes (years) & $14(8-21)$ & $14(5-21)$ & 0.62 \\
\hline Gestational age at inclusion (days) & $66(59-75)$ & $63(57-79)$ & 0.54 \\
\hline Nulliparous & $47(70)$ & $54(57)$ & 0.09 \\
\hline Pre-pregnancy BMI (kg/m²) & $24.4(21.5-28.6)$ & $24.4(22.0-29.1)$ & 0.77 \\
\hline Smoking & $8(12)$ & $8(9)$ & 0.49 \\
\hline Northern European origin & $60(91)$ & $83(87)$ & 0.48 \\
\hline \multicolumn{4}{|l|}{ HbA1c before pregnancy } \\
\hline$\%$ & $7.0(6.6-7.9)$ & $7.0(6.6-7.9)$ & 0.93 \\
\hline $\mathrm{Mmol} / \mathrm{mol}$ & $53(49-63)$ & $53(49-63)$ & \\
\hline \multicolumn{4}{|l|}{$\mathrm{HbA} 1 \mathrm{c}$ at 9 weeks } \\
\hline$\%$ & $6.5(6.2-6.9)$ & $6.5(6.0-7.0)$ & 0.52 \\
\hline $\mathrm{Mmol} / \mathrm{mol}$ & $48(44-52)$ & $47(42-53)$ & \\
\hline \multicolumn{4}{|l|}{$\mathrm{HbA} 1 \mathrm{c}$ at 20 weeks } \\
\hline$\%$ & $6.1(5.7-6.5)$ & $6.1(5.5-6.4)$ & 0.39 \\
\hline $\mathrm{Mmol} / \mathrm{mol}$ & $43(39-48)$ & $43(37-46)$ & \\
\hline \multicolumn{4}{|l|}{$\mathrm{HbA} 1 \mathrm{c}$ at 35 weeks } \\
\hline$\%$ & $6.0(5.6-6.5)$ & $6.1(5.6-6.5)$ & 0.68 \\
\hline $\mathrm{Mmol} / \mathrm{mol}$ & $42(38-47)$ & $43(38-48)$ & \\
\hline Total insulin dose at 9 weeks (IU/kg) & $0.52(0.40-0.66)$ & $0.57(0.47-0.72)$ & 0.06 \\
\hline Total insulin dose at 20 weeks (IU/kg)* & $0.50(0.44-0.70)$ & $0.57(0.47-0.75)$ & 0.47 \\
\hline Total insulin dose at 35 weeks (IU/kg)** & $0.93(0.65-1.19)$ & $0.82(0.60-1.21)$ & 0.41 \\
\hline Events with mild hypoglycemia per week at 9 weeks & $7(3-10)$ & $5(3-9)$ & 0.48 \\
\hline Events with mild hypoglycemia per week at 20 weeks*** & $3(2-5)$ & $3(1-5)$ & 0.89 \\
\hline Events with mild hypoglycemia per week at 35 weeks $* * * *$ & $3(2-5)$ & $3(2-7)$ & 0.56 \\
\hline Systolic office blood pressure $(\mathrm{mmHg})$ at 9 weeks & $116 \pm 10$ & $118 \pm 11$ & 0.24 \\
\hline Diastolic office blood pressure $(\mathrm{mmHg})$ at 9 weeks & $74 \pm 7$ & $75 \pm 7$ & 0.19 \\
\hline Kidney involvement & $6(9)$ & $8(8)$ & 0.30 \\
\hline Microalbuminuria & $3(4.5)$ & $7(7)$ & \\
\hline Diabetic nephropathy & $3(4.5)$ & $1(1)$ & \\
\hline Diabetic retinopathy & $24(37)$ & $38(46)$ & 0.28 \\
\hline Aspirin prescribed in early pregnancy & $53(79)$ & $41(43)$ & $<0.0001$ \\
\hline Antihypertensive treatment during pregnancy & $21(31)$ & $25(26)$ & 0.49 \\
\hline Gestational weight gain $(\mathrm{kg})$ & $12.3(9.3-14.8)$ & $12.2(8.5-14.3)$ & 0.58 \\
\hline
\end{tabular}

Using insulin degludec or other long-acting insulin analogs before and during pregnancy

Data are given as number (\%), mean (SD) or median (interquartile range)

Microalbuminuria was defined as urinary albumin/creatinine ratio $30-299 \mathrm{mg} / \mathrm{g}$

Diabetic nephropathy was defined as urinary albumin/creatinine ratio $\geq 300 \mathrm{mg} / \mathrm{g}$

The individual clinical data were obtained from 94 to $100 \%$ of the women unless otherwise stated: $*_{n}=106 ; * * n=94 ; * * * n=114 ; * * * * n=101$

degludec before conception continue to use this insulin during pregnancy. This is in line with how the insulin analogs lispro $[28,29]$ and insulin glargine $[6,30]$ were introduced to pregnant women with diabetes.

This is the largest study on pregnancy outcomes in women with type 1 diabetes using insulin degludec both before and throughout pregnancy. The data were collected prospectively under routine conditions in a real-world setting [21], and the development of preeclampsia was carefully assessed. The original study focused on hypertension in pregnancy [20,21], but other pregnancy and neonatal outcomes were also reported. We considered the present cohort as a unique opportunity to evaluate data on the use of insulin degludec during pregnancy under real-world conditions. 
Table 2 Maternal pregnancy outcomes and neonatal outcomes in 162 pregnancies of women with type 1 diabetes using insulin degludec or other long-acting insulin analogs before and during pregnancy

\begin{tabular}{|c|c|c|c|}
\hline & $\begin{array}{l}\text { Insulin degludec } \\
(n=67)\end{array}$ & $\begin{array}{l}\text { Other long-acting } \\
\text { insulin analogs } \\
(n=95)\end{array}$ & $p$-value \\
\hline \multicolumn{4}{|l|}{ Maternal pregnancy outcomes: } \\
\hline Preeclampsia & $7(10)$ & $8(8)$ & 0.66 \\
\hline Delivery with preeclampsia before 37 weeks & $2(3)$ & $6(6)$ & 0.47 \\
\hline Mode of delivery: & & & 0.37 \\
\hline Vaginal & $35(52)$ & $52(55)$ & \\
\hline Elective cesarean section & $17(25)$ & $16(17)$ & \\
\hline Emergency cesarean section* & $15(23)$ & $27(28)$ & \\
\hline \multicolumn{4}{|l|}{ Neonatal outcomes: } \\
\hline Gestational age at delivery (days) & $265(261-268)$ & $262(259-267)$ & 0.27 \\
\hline Preterm delivery ( $<37$ weeks) & $11(16)$ & $22(23)$ & 0.29 \\
\hline Birth weight (g) & $3510(3118-3885)$ & $3514(3125-3796)$ & 0.91 \\
\hline Birth weight $z$ score & $0.95 \pm 1.4$ & $0.99 \pm 1.3$ & 0.85 \\
\hline Small for gestational age infants & $3(4)$ & $5(5)$ & 1.0 \\
\hline Large for gestational age infants & $25(37)$ & $37(39)$ & 0.83 \\
\hline Perinatal mortality & 0 & 0 & - \\
\hline Admission to neonatal intensive care unit & $16(24)$ & $22(23)$ & 0.87 \\
\hline Neonatal hypoglycemia $(<2.2 \mathrm{mmol} / \mathrm{l})$ & $21(32)$ & $34(41)$ & 0.28 \\
\hline Transient tachypnea of the newborn & $9(14)$ & $10(11)$ & 0.56 \\
\hline Neonatal jaundice & $16(24)$ & $18(19)$ & 0.44 \\
\hline Apgar score $<7$ at $5 \mathrm{~min}$ & 0 & 0 & - \\
\hline Major congenital malformation & $1(1)$ & $1(1)$ & 1.0 \\
\hline
\end{tabular}

Data are given as number (\%), mean (SD) or median (interquartile range)

*Cesarean section $<8 \mathrm{~h}$ from decision making

The individual clinical data were obtained from $\geq 99 \%$ of the women or infants, except neonatal hypoglycemia where data were obtained from $148(91 \%)$ of the infants
However, data on basal insulin doses were not collected in the original study $[20,21]$ and were therefore not available in this secondary analysis. We acknowledge this as a limitation in this study. Continuous glucose monitoring (CGM) was only used in selected women in this cohort. Therefore, data on use of CGM are not available in this study. Likewise, despite being the largest cohort so far of women using insulin degludec during pregnancy, we also acknowledge that the observational study design and the relatively small sample size limit our possibility to elucidate the safety in details. Larger studies in pregnant women with diabetes, preferably as RCTs, are warranted to evaluate the efficacy and safety in detail. Likewise, cohort studies or registry studies are needed to evaluate rare neonatal complications as congenital malformations and perinatal mortality.

The lack of data on severe hypoglycemia (requiring thirdparty assistance [31]) is also a limitation of this study. However, in our previous publication on 22 women with type 1 diabetes using insulin degludec from conception until after delivery, the prevalence of severe hypoglycemia was low [19]. Likewise, in previous case reports no women using insulin degludec during pregnancy reported severe hypoglycemia [13-17].
Data on number of women planning their pregnancies were not available in this study, but generally a high proportion of pregnancies in women with type 1 diabetes are unplanned [32]. The increasing use of insulin degludec therefore leads to more women becoming pregnant while using this insulin [13, 15-17]. When considering whether to continue insulin degludec or to change to another longacting insulin analog and risk temporary worsening of glycemic control due to insulin change $[17,19]$, data from this study may be helpful for this decision.

To conclude, we found similar pregnancy outcomes with insulin degludec and other long-acting insulin analogs in women with type 1 diabetes, suggesting that insulin degludec initiated before pregnancy may be continued throughout gestation.

Acknowledgements L. Ringholm has received a research grant from Novo Nordisk (Grant Number: U1111-1209-6358) for an investigatorsponsored study.

\section{Declarations}

Conflict of interest ERM have received fees for giving talks for Novo Nordisk A/S. ERM, PD and LR are participating in multicenter and 
multinational clinical studies on the use of insulin in pregnant women with preexisting diabetes in collaboration with Novo Nordisk; no personal honorarium is involved. NCD is funded by Novo Nordisk Foundation.

Ethical standard statement This study was in accordance with the Helsinki declaration. In addition, the study was approved by The National Committee on Health Research Ethics (H-15019186 and H-15009413) and The Danish Data Protection Agency (2012-58-0004, RH-2015-289, I-Suite: 04305).

Informed consent disclosure All participants gave written informed consent before the data collection.

\section{References}

1. Bacon S, Feig DS (2018) Glucose targets and insulin choice in pregnancy: what has changed in the last decade? Curr Diab Rep 18:77

2. de Jong J, Garne E, Wender-Ozegowska E, Morgan M, de Jongvan den Berg LT, Wang H (2016) Insulin analogues in pregnancy and specific congenital anomalies: a literature review. Diabetes Metab Res Rev 32:366-375

3. Mathiesen ER, Damm P, Jovanovic L et al (2011) Basal insulin analogues in diabetic pregnancy: a literature review and baseline results of a randomised, controlled trial in type 1 diabetes. Diabetes Metab Res Rev 27:543-551

4. Mathiesen ER, Hod M, Ivanisevic M et al (2012) Maternal efficacy and safety outcomes in a randomized, controlled trial comparing insulin detemir with NPH insulin in 310 pregnant women with type 1 diabetes. Diabetes Care 35:2012-2017

5. Mathiesen ER, Ali N, Alibegovic AC et al (2021) Risk of major congenital malformations or perinatal or neonatal death with insulin detemir versus other basal insulins in pregnant women with preexisting diabetes: the real-world EVOLVE study. Diabetes Care 44:2069

6. Callesen NF, Damm J, Mathiesen JM, Ringholm L, Damm P, Mathiesen ER (2013) Treatment with the long-acting insulin analogues detemir or glargine during pregnancy in women with type 1 diabetes: comparison of glycaemic control and pregnancy outcome. J Matern Fetal Neonatal Med 26:588-592

7. Ringholm L, Damm P, Mathiesen ER (2019) Improving pregnancy outcomes in women with diabetes mellitus: modern management. Nat Rev Endocrinol 15:406-416

8. Toledano Y, Hadar E, Hod M (2018) Pharmacotherapy for hyperglycemia in pregnancy - the new insulins. Diabetes Res Clin Pract 21:1127

9. Haahr H, Heise T (2014) A review of the pharmacological properties of insulin degludec and their clinical relevance. Clin Pharmacokinet 53:787-800

10. Bode BW, Buse JB, Fisher M et al (2013) Insulin degludec improves glycaemic control with lower nocturnal hypoglycaemia risk than insulin glargine in basal-bolus treatment with mealtime insulin aspart in Type 1 diabetes (BEGIN((R)) BasalBolus Type 1): 2-year results of a randomized clinical trial. Diabet Med 30:1293-1297

11. Davies MJ, Gross JL, Ono Y et al (2014) Efficacy and safety of insulin degludec given as part of basal-bolus treatment with mealtime insulin aspart in type 1 diabetes: a 26 -week randomized, open-label, treat-to-target non-inferiority trial. Diabetes Obes Metab 16:922-930

12. Lane W, Bailey TS, Gerety G et al (2017) Effect of insulin degludec versus insulin glargine U100 on hypoglycemia in patients with type 1 diabetes: the SWITCH 1 randomized clinical trial. JAMA 318:33-44

13. Bonora BM, Avogaro A, Fadini GP (2019) Exposure to insulin degludec during pregnancy: report of a small series and review of the literature. J Endocrinol Invest 42:345-349

14. Hiranput S, Ahmed SH, Macaulay D, Azmi S (2019) Successful outcomes with insulin degludec in pregnancy: a case series. Diabetes Ther 10:283-289

15. Milluzzo A, Tumminia A, Scalisi NM, Frittitta L, Vigneri R, Sciacca L (2017) Insulin degludec in the first trimester of pregnancy: report of two cases. J Diabetes Investig 9:629

16. Roman-Gonzalez A, Builes-Barrera CA, Aristizabal BA (2019) Exposure to degludec during pregnancy: a case report. Cureus 11:e5158

17. Sprio E, Lucotti $\mathrm{P}$, Iadarola C, Bellingeri C, Beneventi F, Lovati E (2021) Use of insulin degludec in pregnancy: two case reports and a literature review. Endocr Metab Sci 1:100064

18. European Medicines Agency Degludec label. https://www.ema. europa.eu/en/documents/product-information/tresiba-eparproduct-information_en.pdf. Accessed on December 7th 2021

19. Keller MF, Vestgaard M, Damm P, Mathiesen ER, Ringholm L (2019) Treatment with the long-acting insulin analog degludec during pregnancy in women with type 1 diabetes: an observational study of 22 cases. Diabetes Res Clin Pract 152:58-64

20. Do NC, Vestgaard M, Asbjornsdottir B et al (2021) Unchanged prevalence of preeclampsia after implementation of prophylactic aspirin for all pregnant women with preexisting diabetes: a prospective cohort study. Diabetes Care 44:2252

21. Vestgaard M, Asbjornsdottir B, Ringholm L et al (2019) White coat hypertension in early pregnancy in women with pre-existing diabetes: prevalence and pregnancy outcomes. Diabetologia 62:2188-2199

22. Nielsen LR, Pedersen-Bjergaard U, Thorsteinsson B, Johansen M, Damm P, Mathiesen ER (2008) Hypoglycemia in pregnant women with type 1 diabetes: predictors and role of metabolic control. Diabetes Care 31:9-14

23. Pedersen-Bjergaard U, Pramming S, Thorsteinsson B (2003) Recall of severe hypoglycaemia and self-estimated state of awareness in type 1 diabetes. Diabetes Metab Res Rev 19:232-240

24. Jensen DM, Damm P, Sorensen B et al (2003) Pregnancy outcome and prepregnancy body mass index in 2459 glucose-tolerant Danish women. Am J Obstet Gynecol 189:239-244

25. American Diabetes Association (2018) Standards of Medical Care in Diabetes- 2018. Diabetes Care 41:137-143

26. Hypertension in Pregnancy (2013) Report of the American College of Obstetricians and Gynecologists' task force on hypertension in pregnancy. Obstet Gynecol 122:1122-1131

27. Marsal K, Persson PH, Larsen T, Lilja H, Selbing A, Sultan B (1996) Intrauterine growth curves based on ultrasonically estimated foetal weights. Acta Paediatr 85:843-848

28. European Medicines Agency Lispro label. http://www.ema. europa.eu/docs/en_GB/document_library/EPAR_-_Product_ Information/human/004303/WC500235294.pdf. Accessed on December 7th 2021

29. Lapolla A, Dalfra MG, Spezia R et al (2008) Outcome of pregnancy in type 1 diabetic patients treated with insulin lispro or regular insulin: an Italian experience. Acta Diabetol 45:61-66

30. European Medicines Agency Lantus label. http://www.ema. europa.eu/docs/en_GB/document_library/EPAR_-_Product_ Information/human/000284/WC500036082.pdf. Accessed on December 7th 2021

31. Seaquist ER, Anderson J, Childs B et al (2013) Hypoglycemia and diabetes: a report of a workgroup of the American Diabetes Association and the Endocrine Society. Diabetes Care 36:1384-1395 
32. Murphy HR, Steel SA, Roland JM et al (2011) Obstetric and perinatal outcomes in pregnancies complicated by Type 1 and Type 2 diabetes: influences of glycaemic control, obesity and social disadvantage. Diabet Med 28:1060-1067
Publisher's Note Springer Nature remains neutral with regard to jurisdictional claims in published maps and institutional affiliations. 